OPEN ACCESS

Edited by:

Di Jin,

Woods Hole Oceanographic

Institution, United States

Reviewed by:

Jessica M. Frazier,

University of Rhode Island,

United States

Rachel Gjelsvik Tiller,

SINTEF, Norway

${ }^{*}$ Correspondence:

Marysia Szymkowiak

marysia.szymkowiak@noaa.gov

Specialty section:

This article was submitted to

Marine Affairs and Policy,

a section of the journal

Frontiers in Marine Science

Received: 23 February 2020

Accepted: 14 April 2020

Published: 08 May 2020

Citation:

Szymkowiak $M$ and

Rhodes-Reese M (2020) Addressing the Gender Gap: Using Quantitative and Qualitative Methods to Illuminate

Women's Fisheries Participation.

Front. Mar. Sci. 7:299.

doi: 10.3389/fmars.2020.00299

\section{Addressing the Gender Gap: Using Quantitative and Qualitative Methods to Illuminate Women's Fisheries Participation}

\author{
Marysia Szymkowiak ${ }^{1 *}$ and Melissa Rhodes-Reese ${ }^{2}$ \\ 'Alaska Fisheries Science Center, National Marine Fisheries Service, Juneau, AK, United States, ${ }^{2}$ Pacific States Marine \\ Fisheries Commission, Alaska Fisheries Science Center, National Marine Fisheries Service, Juneau, AK, United States
}

While key to the sustainability of fisheries, women's contributions to this sector are largely outside of the conventional discourse on fisheries participation and remain poorly understood and unrecognized. Furthermore, the research on women's engagement in fisheries has largely focused on small-scale fisheries in a development context. This study extends this geographic focus by using a systematic analysis of the literature to explore how women's fisheries participation has been examined in developed countries in Europe and North America. We demonstrate the preponderance of themes and methodologies that have been utilized in these regions, highlighting the reliance on case studies employing qualitative methods due in part to the dearth of gender disaggregated data in this sector. Although such methods can yield a deep understanding, the results are often limited in geographic scope and generalizability. In response, we present a methodological approach that can extend the scope of research and comprehensively examine women's participation across its multifaceted dimensions. We demonstrate the accuracy of a freely available software to predict gender using limited personal information and apply it to harvest data in Alaska, addressing the previous impediment of a lack of a gender attribute within fisheries datasets and extending the methodological applications to include quantitative methods. This is coupled with focus groups across highly engaged fishing communities in the Gulf of Alaska to integrate the multiple themes that have been explored in the literature on women's fisheries participation, evidencing the utility of a mixed-methods approach to explore the multi-faceted nature of women's fisheries engagement.

Keywords: fisheries management, gender disaggregated data, mixed-methods, women and fisheries, Alaska

\section{INTRODUCTION}

The fisheries workforce is not immune to the social construct of gender that affects norms of behavior, opportunities and access, power relations, and political dynamics. Throughout this study we use the term "gender" as opposed to "sex" because the former relates to social roles while the latter is used in the context of biological differences (Ogle and Schanning, 2012). Within fisheries, gender power dynamics may most readily manifest themselves in differentiated access 
and labor divisions as well as the way managers perceive user groups. The societal values associated with gender and subsequent divisions are revealed in how fisheries participation is tracked (FAO, 2017). Globally, gender disaggregated data is rarely collected and this ultimately inhibits our understanding of women's participation in fisheries (Aguilar and Castaneda, 2001; Frangoudes et al., 2008; Gopal et al., 2014). When disaggregated data are collected, the data is often constrained to direct harvesting activities, thus eliminating the vast majority of women participants, who largely occupy the pre and post-harvesting sector across the globe (FAO, 2016).

Herein, the role of gender within fisheries is explored as a binary construct to aid in the analysis and to explore the integration of a gender variable into fisheries datasets using freely available software, which currently constrains defining gender to its biological interpretation (i.e., male and female). This unfortunately ignores the non-binary nature of how many individuals perceive their own gender, as well as the importance of intersectionality among various demographic variables and how it shapes the manifestation of gender (Crenshaw, 1989, 1997; Collins, 1998; Crenshaw and Bonis, 2005). However, for the purposes of this study it is a necessary simplification to illuminate patterns in how men and women differentially access, participate in, and benefit from fisheries and to advance the discussion by presenting a methodology of examining these various dimensions.

The lack of gender information and a nuanced understanding of women's participation in fisheries enables policies that largely ignore gender, which can in turn lead to management inadvertently operating under gender biases (Williams, 2010). Women's engagement in fisheries tends to diverge from men's, with their participation often being intermittent, reflecting their adaptations to personal and family conditions that may alter their ability or necessity to directly participate (Porter, 1985; Nadel-Klein, 2000). This differing pattern of participation can affect their status and empowerment in fisheries, which can be exacerbated by gender blind management programs that change access to the resource (Uden, 2009; Britton, 2012; Zhao et al., 2013). For example, professionalization schemes that allocate fishing privileges on the basis of experience can disadvantage and marginalize women; and, given that such privileges frequently become highly valuable, women's market power may ultimately be reduced, further inhibiting their access (Munk-Madsen, 2000; Nadel-Klein, 2000; Grzetic, 2004; Power, 2005). Similarly, it is common for women to harvest in areas isolated from men using different gear types and because of this, management policies intended to curtail harvests or protect resources through instituting area closures or gear restrictions can also have a significant gendered effect (Lavoie et al., 2019).

A lack of understanding of women's participation in fisheries can also lead to unforeseen consequences of management and other changes in fishing conditions. As direct participants, women may have responses to fishery changes that are different from men due to inter alia differing opportunity costs, risk thresholds, occupational identities, and fishing portfolios (Kleiber et al., 2015). Women are also critical to shaping the resilience of fishing families due to their adaptive roles, but the invisibility of these functions may lead to responses that diverge from expectations (Binkley, 2000; Nadel-Klein, 2000; Grzetic, 2004). For example, women may replace paid crewmembers on board family fishing vessels to try to buffer household incomes against revenue declines associated with fishery changes (Munk-Madsen, 1998; Grzetic, 2004). Yet the displacement of paid crew may be to the detriment of isolated fishing communities where alternative employment opportunities are limited and thus contrary to management provisions intended to mitigate the effects of regime changes (Olson, 2011; Carothers and Chambers, 2012; Szymkowiak and Himes-Cornell, 2015).

Much of the work in gender and fisheries has focused on women's participation in small scale fisheries in developing countries, which as others have noted may in part be due to the roots of gender in fisheries research within the field of development (Walker and Robinson, 2009; Kleiber et al., 2015). Indeed, the literature on women's fisheries engagement in developed countries is largely contextualized within fishing families (Frangoudes and Keromnes, 2008; Britton, 2012; Calhoun et al., 2016), which while potentially revealing the predominant route for women's participation in these countries may also ignore broader issues of access and equity by focusing on a population with potentially inherently greater accessibility. Furthermore, there is a similar dearth of gender-disaggregated data in these regions as elsewhere in the world (Williams, 2010; Frangoudes, 2013), constraining comprehensive examinations of women's fisheries participation.

The intent of this study is to build on this existent work and expand the geographic focus of the literature to examine the information gaps and research needs related to the dynamics of women's participation in marine commercial fisheries in developed countries within North America and Europe. Examining women's fisheries participation across developed countries is intended to move the literary discourse of women's engagement beyond issues of development to focus on access and mobility within fisheries in the context of greater economic opportunities.

We systematically analyze the current literature on women's commercial fisheries participation in these regions identifying systemic themes in how that participation is examined and the methodologies that are applied. We identify methodological gaps and the intertwined nature of the themes, which in turn illustrates the variegated and dynamic ways in which women participate in fisheries and the areas that necessitate more research. We then present a methodology that examines women's direct and indirect fisheries participation, by incorporating a gender attribute into existent data to track direct participation and by using focus groups to understand multiple dimensions of participation that cannot be deduced from the data alone. This mixed-methods approach is applied to examine women's fisheries participation in Alaska, revealing gender disparities in participation and dimensions of engagement. 


\section{LITERATURE REVIEW METHODS}

We used multiple scholarly literature search databases (Scopus, Google Scholar, EBSCOhost, JSTOR) and search terms including "women and fisheries," "women and fish," "gender and fisheries," "gender and fish," and "female and fisheries" to identify English language peer-reviewed publications, with no limitations on publication date. (Search terms combining "female and fish," or any that included "sex" resulted in papers that discussed the sex of the actual fish rather than the gender of participants; therefore, these terms were ultimately omitted as irrelevant). We further narrowed that list to publications specific to developed countries within North America and Europe, while retaining those with a broader geographic focus if they included case studies within our region of interest. This second step necessitated actually skimming through each study since the geographic extent was often not readily apparent from the title or abstract. In addition we examined all of the publications that were cited in the peer-reviewed literature that we found using the search databases. In general we limited our analysis to peerreviewed publications, except in several cases where Master's or Doctoral theses were relevant to women in fisheries and fishing communities (Grzetic, 2004; Donkersloot, 2005; Gonzalez, 2018), and reports commissioned by the European Union (EU) that discussed women's participation in detail in the context of the literature and presented secondary data on that participation not published elsewhere (European Commission Directorate General for Fisheries, 2000).

This analysis focuses specifically on women's engagement in commercial marine fisheries (excluding aquaculture), in line with the method that we present for examining women's participation. We define commercial participation as dealing with any harvest or processing undertaken with the intention of selling, as opposed to personal or household consumption, sharing, or bartering. Focusing specifically on women in commercial fisheries allows us to examine participation with respect to economic independence, occupational identity, and women's contribution to the fishing industry more broadly.

Because the method that we present is specific to commercial fisheries participation, we excluded from our review literature that focused exclusively on women's participation as subsistence or recreational users. There is also an emerging body of literature specific to the integration of women's perspectives into marine governance processes that was excluded from our analysis unless it explicitly examined women's participation in fisheries as well. We also excluded publications within compendiums that replicated material already published in peer-reviewed literature by the same author; however, we did include publications within these compendiums that did not have a counterpart in the peer-reviewed literature. On the basis of the above sampling framework we identified a total of 65 publications that examine women's participation in fisheries as either the central or one of the major themes of the study within the target countries, with publication dates ranging from 1984 to 2019.

The publications were thematically coded to determine the major topic areas that have been examined in the literature with respect to women's commercial fisheries participation in developed countries within North America and Europe. In addition, the methodology applied and country or geographic region studied were recorded for each publication. The geographic and methodological distributions of the studies elucidate where and how the overarching themes of women's participation in commercial fisheries have been evaluated, highlighting critical gaps. Figures were prepared using the $\mathrm{R}$ packages "ggplot2" (Wickham, 2009), "maps" (Becker and Wilks, 2018) and "lattice" (Sarkar, 2008). All code is available from the authors upon request, inclusive of analyses described in Sections "EXAMINING THE GEOGRAPHIC COVERAGE, THEMATIC SCOPE, AND METHODOLOGIES EMPLOYED IN THE LITERATURE ON WOMEN'S FISHERIES PARTICIPATION" and "A METHOD FOR EXAMINING WOMEN'S FISHERIES ENGAGEMENT APPLIED TO ALASKA” below.

\section{EXAMINING THE GEOGRAPHIC COVERAGE, THEMATIC SCOPE, AND METHODOLOGIES EMPLOYED IN THE LITERATURE ON WOMEN'S FISHERIES PARTICIPATION}

\section{Geographic Coverage}

Building on previous efforts conducted by Kleiber et al. (2015) and others, which focused on women's participation in small scale fisheries including for subsistence purposes, Figure $\mathbf{1}$ highlights the distribution of studies within the target countries focused on commercial marine fisheries. There are substantial disparities across the countries in terms of the number of studies that shed any light on women's participation in commercial marine fisheries. The vast majority of the countries have fewer than 10 studies, with many among this cohort that are discussed as part of broader literature reviews or meta-analyses, as opposed to research targeting a specific country or region.

In addition to the generally limited number of studies that examine women's participation in the study countries, the geographic coverage of the research explored in this study is largely limited to the community level. Within Canada, for example, despite the apparent large number of studies, only one has been outside of Newfoundland. As discussed in more detail below, the geographic scope of much of this literature is in part constrained by the lack of gender disaggregated data, which largely restricts researchers to utilizing qualitative methods that are often inherently limited in geographic coverage.

\section{Thematic Scope}

Across the study countries, women's participation in fisheries is strikingly homogeneous in its various characteristics, heavily influenced by their caregiving and domestic responsibilities and predominantly occurring within the pre and post-harvesting sector. Table 1 shows the major themes in women's commercial fisheries participation that are examined in the literature specific to women's participation in commercial marine fisheries in developed countries in North America and Europe, as well as the number of times the theme is captured, with brief 

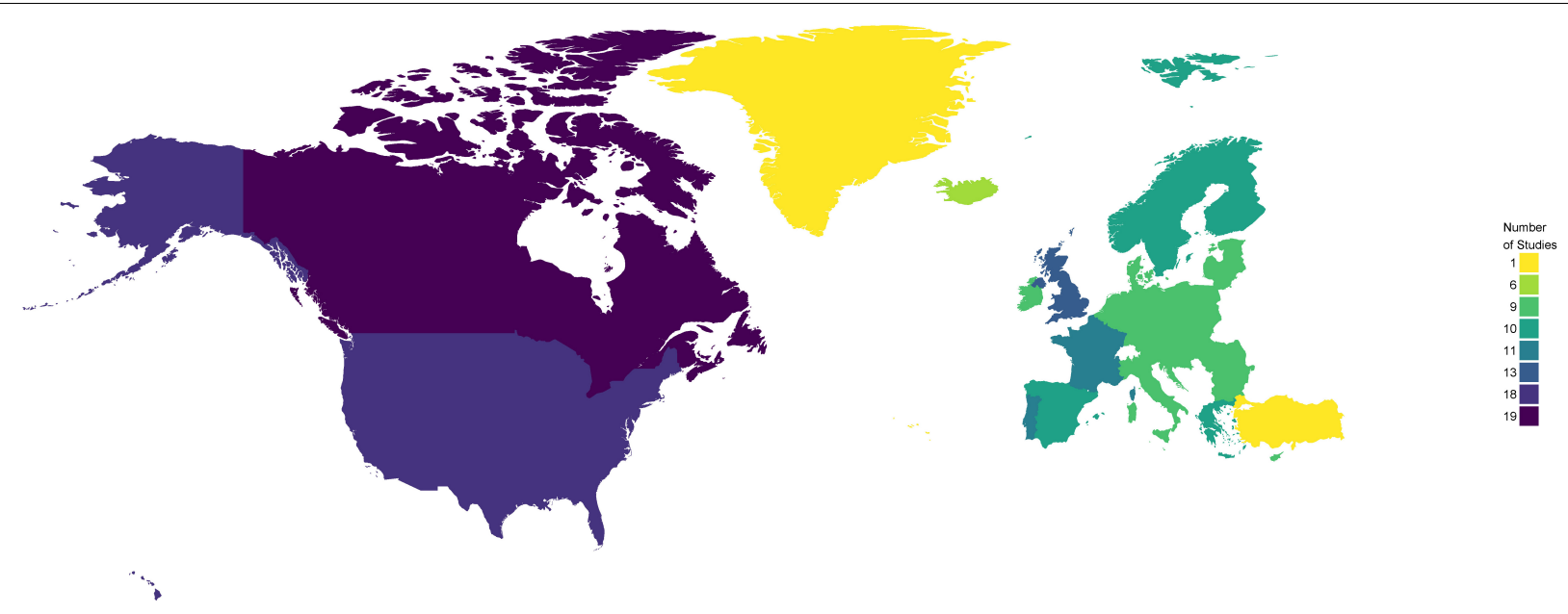

FIGURE 1 | Geographic coverage of literature on women's fisheries participation. Note that the scale is not continuous but rather accommodates the actual number of studies by country: Azores, Finland, Greenland, Turkey, Iceland, Austria, Belgium, Bulgaria, Croatia, Cyprus, Czech Republic, Denmark, Estonia, France, Germany, Greece, Hungary, Ireland, Italy, Latvia, Lithuania, Luxembourg, Malta, Netherlands, Poland, Portugal, Romania, Slovakia, Slovenia, Spain, Norway, The

United Kingdom, United States, and Canada. All EU countries were included for studies dedicated to reviewing gender in fisheries across the whole EU or "Europe" in general with EU country examples.

descriptions of the concepts relevant to each of them. The narrative below describes the dominant nuances of how those themes are discussed in the literature. Only some of the citations specific to each thematic area are included in the following narrative; the Supplementary Material includes a list of the literature incorporated in this analysis and associated thematic and geographic areas and methodologies.

\section{Women's Unrecognized and Undervalued Contributions to Fishing Families and Communities}

As previously noted, women's commercial fisheries participation in developed countries is frequently contextualized in the literature with respect to their "roles in family fishing operations." From getting bait and fuel, participating as crew, doing paperwork and accounting, to processing and selling catch, women are integral to the operations of commercial family fishing vessels (Bates, 2006; Calhoun et al., 2016; Frangoudes and Gerrard, 2019). However, women's roles in these families are often considered extensions of domestic work even to the women themselves who may devalue their contribution in discourse that juxtaposes their labor to that of their fishing partner (Grzetic, 2004; Yodanis, 2000; Karlsdóttir, 2009). While key to sustaining family operations and in turn fishing communities more broadly, women's contributions within the fishing family context are largely ignored as they are often deemed less valuable than direct harvesting participation. These concepts are captured under "perceptions of work," which also extends to how women's labor within the fishing industry is perceived and, in turn valued, more broadly (Williams, 2010; Salmi and Sonck-Rautio, 2018). A number of studies discuss the evolution of this valuation in terms of legal frameworks in Europe that have been undergoing revisions over the last decade to formally recognize women's contributions to fishing families and thus ensure their access to social nets that have previously only been available to harvesters
(European Commission Directorate General for Fisheries, 2000; Frangoudes and Keromnes, 2008; Frangoudes et al., 2008).

Women perform an array of roles within their families, whether those families run commercial fishing operations or otherwise, which necessitates constant juggling that affects whether and how women participate in fisheries. The "dimensions of labor" theme was thus formulated to encapsulate when the discussion in the literature shifts to women's navigation of these multiple roles within their families. This includes women's roles beyond their participation in sustaining the fishing operation such as domestic and caregiving responsibilities and shoreside employment outside of the fisheries sector (Uden, 2009; Lavoie et al., 2019). These numerous roles and this navigation process are often discussed in the literature with respect to the disproportionate burden within families and societies more broadly that are placed upon women (Skaptadóttir, 1996; Power, 2005; Salmi and Sonck-Rautio, 2018).

Women sustain fishing communities far beyond their support of family fishing operations, as noted by researchers who discuss the roles of women in developing social networks that help to bind fishing communities (Davis, 1986; Skaptadóttir, 1996; Nadel-Klein, 2000). These networks are often critical to a number of functions including expediting fisheries participation, marketing fish, and supporting fishing participants and families through times of adversity. In addition, fisheries organizations spearheaded by women are often engaged in the political process and advocate for the role of fisheries in defining community identity (Conway et al., 2002; Calhoun et al., 2016). In addition to at times supporting and other times engendering an individual and collective fishing identity within communities, the theme of "identity" encapsulates the complex relationships that women often have with tying a sense of self and family to an occupation. For example, Donkersloot (2005) describes gendered responses to ecological crisis in Bristol Bay salmon fisheries with women 
TABLE 1 | Major themes described in the literature on women's participation in fisheries.

\begin{tabular}{|c|c|}
\hline Theme & Description \\
\hline $\begin{array}{l}\text { Influences on participation } \\
(n=33)\end{array}$ & $\begin{array}{l}\text { Includes barriers (e.g., taboos, } \\
\text { stereotypes, cultural norms) and factors } \\
\text { that may increase participation (e.g., } \\
\text { evolution of norms, necessity, } \\
\text { opportunity) }\end{array}$ \\
\hline $\begin{array}{l}\text { Roles in family fishing operation } \\
(n=55)\end{array}$ & $\begin{array}{l}\text { All activities related to facilitating family } \\
\text { fishing operation }\end{array}$ \\
\hline Perceptions of work $(n=38)$ & $\begin{array}{l}\text { Inclusive of notions about the value of } \\
\text { women's contributions and the } \\
\text { invisibility of their work }\end{array}$ \\
\hline $\begin{array}{l}\text { Participation in } \\
\text { management/policy }(n=24)\end{array}$ & $\begin{array}{l}\text { Consideration of women in fisheries } \\
\text { policy-making and management }\end{array}$ \\
\hline Fishing identity $(n=19)$ & $\begin{array}{l}\text { Includes women's influence on and } \\
\text { internalization of fishing identity at the } \\
\text { individual, family, and community level }\end{array}$ \\
\hline Dimensions of labor $(n=30)$ & $\begin{array}{l}\text { Roles and responsibilities beyond those } \\
\text { affecting the family fishing operation } \\
\text { and related to women's participation in } \\
\text { fisheries }\end{array}$ \\
\hline $\begin{array}{l}\text { Direct harvest participation } \\
(n=34)\end{array}$ & $\begin{array}{l}\text { All activities related to women's direct } \\
\text { participation in harvesting, includes } \\
\text { gleaning and gathering }\end{array}$ \\
\hline $\begin{array}{l}\text { Impacts of management } \\
(n=22)\end{array}$ & $\begin{array}{l}\text { Including effects of management } \\
\text { changes (quota systems, gear/area } \\
\text { restrictions, etc.) on direct participation } \\
\text { and within fishing family operation }\end{array}$ \\
\hline $\begin{array}{l}\text { Impacts of fisheries crisis } \\
(n=21)\end{array}$ & $\begin{array}{l}\text { Including effects of crises (stock or } \\
\text { price declines, other environmental } \\
\text { issues, etc.) on direct participation and } \\
\text { within fishing family operation }\end{array}$ \\
\hline $\begin{array}{l}\text { Pre and post-harvest activities } \\
(n=39)\end{array}$ & $\begin{array}{l}\text { All activities related to facilitating } \\
\text { fisheries prior to and after harvest, } \\
\text { beyond family unit }\end{array}$ \\
\hline Participation over time $(n=19)$ & $\begin{array}{l}\text { Encompasses cumulative effects } \\
\text { across different theme areas that has a } \\
\text { temporal dimension }\end{array}$ \\
\hline
\end{tabular}

migrating out of the communities for employment while men remain. Nearly 15 years later in the same region, Lavoie et al. (2019) describe the internalization of a fishing identity among women, who then seek to similarly imprint that identity upon future generations.

\section{Women's Pre, Post, and Direct Harvesting Participation}

While contributing to the sustainability of fishing families and communities, women's domestic and caregiving roles often conflict with direct harvesting participation in fisheries. This is manifest in women's largely intermittent participation pattern, mostly concentrated in nearshore fisheries conducive to navigating these dynamics (Frangoudes and O'Doherty, 2006; Neilson et al., 2014), nuances that are captured under "direct harvest participation." This theme also encompasses how women's harvesting engagement in developed countries is often constrained to working alongside their male partner, predominantly in a subordinate, crew role (Munk-Madsen, 2000; Bavington et al., 2004; Angell, 2009).
Women's participation in fisheries is influenced by a number of factors that are discussed frequently within the literature. Although not exclusively, these influences are described often with respect to impacts on direct participation in the harvesting sector. Initially we characterized these factors in terms of barriers, including taboos or superstitions about women as bad luck on boats; stereotypes about physical impediments; cultural norms including the perceived masculinity of fishing and limits to women's general economic and sociocultural agency and independence. These sorts of barriers are commonplace in the study countries as they are throughout the world, restricting in which fisheries, when, and how women can participate (McCay, 2003; Helander-Renvall, 2009; Kleiber et al., 2017). However, we found that some factors like the evolution of cultural norms that enable women to participate in the workforce and necessity of additional income actually increased women's fisheries participation so that the theme needed to be expanded to capture these dynamics, thus "influences on participation" (Munk-Madsen, 2000; Grzetic, 2004).

Due in part to these varied influences and their domestic responsibilities, women's participation in fisheries is predominantly within the pre and post-harvest sector. Although oftentimes this is the key role of women within family fishing operations, post-harvest engagement transcends family boundaries and women work from industrial processing plants to fish markets in a mixture of activities that often intertwine processing, marketing, and selling fish (AbreuFerreira, 2000; Kafarowski, 2009; Harper et al., 2013). Women also frequently engage in commercial pre-harvesting activities such as net mending, making gear, and selling bait (Gerrard, 1995; Mercier, 2001). The totality of these concepts as distinct from direct harvesting engagement is captured under "pre-and post-harvest activities."

\section{Implications of Management, Crises, and Time}

Because women's engagement in fisheries in developed countries is often in activities that are either completely not tracked or considered supporting in relation to harvesters, their participation is often unseen and largely described in the literature as "invisible" (Zhao et al., 2013; Pettersen, 2018; Salmi and Sonck-Rautio, 2018). In turn this perception is reflected in women's general absence from fishery management bodies and omission from policy development considerations, concepts that are encapsulated under "participation in fisheries management/policy" (Karlsdóttir, 2009; Williams, 2010; Frangoudes and Gerrard, 2019). Although this theme is also used in cases when women do effectively engage in management (Hall-Arber, 1996; Frangoudes and O'Doherty, 2006; Calhoun et al., 2016).

Researchers have noted that the gender blind nature of many fisheries policies can in turn lead to gender biases that institutionalize norms and patriarchal access to fisheries resources by ignoring the nuances of how women participate (Munk-Madsen, 1998; Frangoudes et al., 2008; Frangoudes and Gerrard, 2019). The "impact of management" theme covers a variegated set of effects including disenfranchisement associated with management schemes intended to limit fisheries access or 
professionalize the fleet with participation requirements (NadelKlein, 2000; Bavington et al., 2004; Power, 2005; Gerrard, 2009) and increasing fishing or shoreside employment burden due to changes that restrict fisheries access or limit family fishing revenues (Connelly and MacDonald, 1991-1992; Bavington et al., 2004). Similarly, women's adaptive roles within fishing families can have adverse implications in the face of fisheries crises ("impacts of fisheries crisis"), which have been shown to inter alia increase the burden of both domestic and paid work on women due to increased absences from their male fishing partner and the necessity of buffering household incomes against fishery revenue declines (Pettersen, 1996; Neis, 1999; Angell, 2009).

Finally, a portion of the literature on women's participation has a temporal dimension that is captured under women's "participation over time." Although in part, these changes may be encompassed under other themes dealing with normative behavior or social effects from management changes or fisheries crises, because the cumulative effect is a fundamental alteration of women's participation, "participation over time" is captured under a separate theme (Abreu-Ferreira, 2000; Keough, 2012).

\section{Parsing Women's Fisheries Participation}

This discussion is intended to showcase the intertwined, complex, and dynamic nature of women's fisheries participation and the themes that exist in the literature. Women occupy a multitude of various roles within the fishing industry, navigating constantly between them in response to personal and external forces. The coding of themes within the literature that discusses these nuances was a necessary oversimplification of these dynamics, intended to demonstrate the overlap across the study regions in how women engage in fisheries while capturing the multifaceted nature of this engagement.

In order to develop a methodology to address these various dimensions, the crux of participation required further parsing, and therefore was simplified down to direct and indirect participation. Direct participation includes harvesting and processing participation that should be captured in data and thus integrated into management frameworks and decisions. Indirect participation, on the other hand, may not be readily examined due to its unseen or undervalued nature and is frequently discussed in the literature in the context of women's roles within fishing families, post-harvesting activities, and absence from policy considerations. It is understood that there is an inherent fluidity between these dimensions of women's fisheries participation. While in some instances women may serve largely support functions within fishing families, they may be able to shift into onboard participation in response to changing fishery conditions or personal circumstances. Thus, understanding these dimensions is critical to conceptualizing potential gendered effects and responses to fishery changes, and in turn formulating policies that achieve their intended objectives, while limiting disproportionately adverse effects on women.

\section{Preponderance of Themes and Methodologies}

The preponderance of these themes across the literature and the tools that have been employed to examine them are captured in
Figure 2. Most papers explore multiple themes and many utilize several methodologies so that the totals across the themes and methods are greater than the 65 total papers that were examined. The figure readily demonstrates the prevalence of several major themes in the literature including roles in family fishing operations, perceptions of work, influences on participation, direct harvest participation, and pre and post-harvest activities, as well as the reliance on qualitative methods - ethnographic fieldwork and interviews in particular - to explore these themes and women's participation in fisheries more broadly. Whereas the examination of some themes including identity, perceptions of work, and influences on participation relies on qualitative research methods due to the depth of explanation that can be achieved with these methods, other themes could benefit from a mixed-methods approach that utilizes quantitative tools to triangulate results, test hypotheses, and systematically examine the role of gender.

Several researchers propose the use of value chain analysis to examine the multiple dimensions of women's direct and indirect participation in fisheries (MacDonald et al., 2008; De Silva, 2011; Williams et al., 2012). This type of analysis examines fisheries as a system from pre-harvest activities to market and consumption, where women's various contributions would be evident along the way and thus be incorporated into policymakers' understanding of fishery dependence and usage. However, a general lack of systematic gender data collections on fisheries participants around the world constrains this type of analysis or our understanding of women's direct participation in fisheries more specifically. Furthermore, women's indirect participation may not be effectively captured in this type of analysis unless there is a comprehensive understanding of women's heretofore unrecognized contributions along the value chain.

The lack of gender disaggregated data inherently limits the methodologies that researchers can employ to examine women's fisheries participation, which is often cataloged using nonquantitative social science research methodologies or primary data collections at small scales to track participants (Harper et al., 2013). For our purposes, secondary data encapsulates data that was not collected during the examined studies. In fact, Figure 2 demonstrates that secondary data was used in only 14 of the studies. Furthermore, that number is inclusive of studies that provided any estimate of women's participation, with multiple authors pointing to issues with the accuracy of available estimates and limitations on the utility of secondary data in its current form to capture women's participation (Frangoudes et al., 2008; Williams, 2010; Frangoudes, 2013; Kleiber et al., 2017; Frangoudes and Gerrard, 2019).

Secondary data used in the examined countries came primarily from national labor statistics that capture employment data (European Commission Directorate General for Fisheries, 2000; Frangoudes, 2013; Júlíusdóttir et al., 2013). For example, Eurostat ${ }^{1}$ is a public database operated by the EU's Statistical Office and houses a multitude of data including the EU Labor Force Survey (LFS). The LFS is a household survey that is conducted by all member states and collects information on

\footnotetext{
${ }^{1}$ https://ec.europa.eu/eurostat
} 


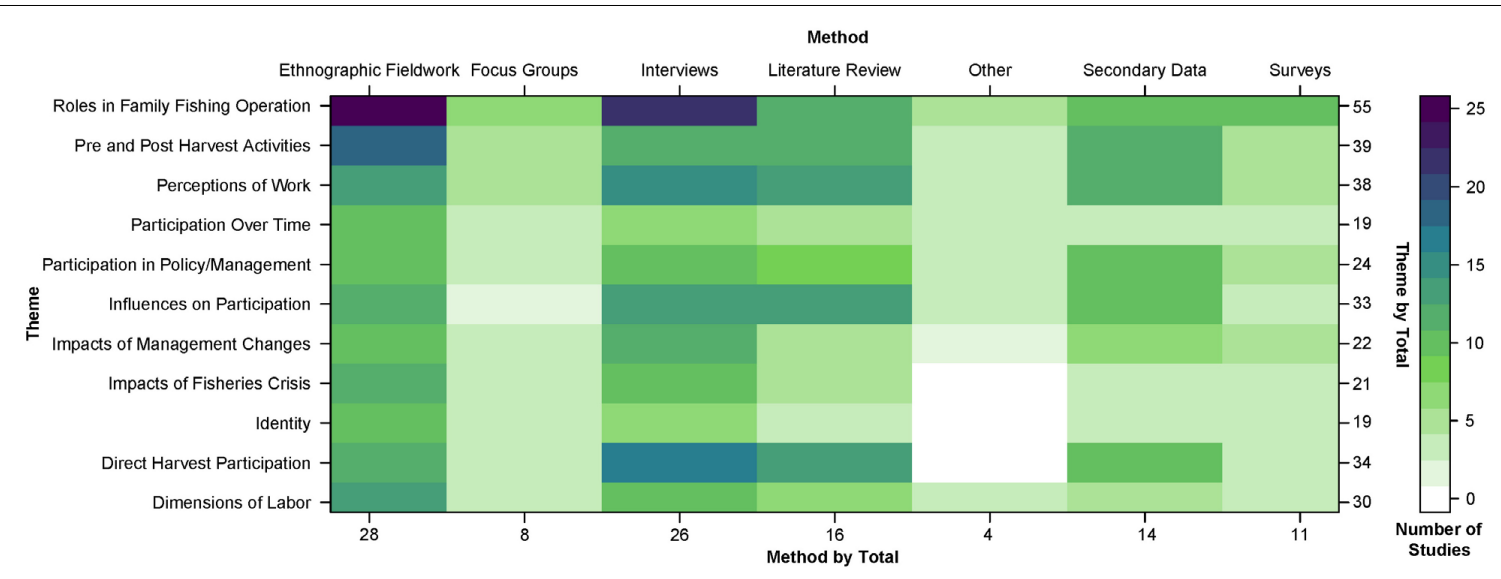

FIGURE 2 | Main themes explored in the literature on women's fisheries participation by method employed to examine them.

individuals' economic activities categorized into codes that relate to occupational categories including agriculture, forestry and fishing. The EU LFS final sampling method and questions are determined by the member countries and assembled by Eurostat. Thus, gender disaggregated data is only recorded for a few countries with the majority of records being noted as unreliable or having significant gaps (European Commission Directorate General for Fisheries, 2000). In addition to Eurostat, the United Nations Food and Agricultural Organization (FAO) ${ }^{2}$ surveys FAO member states and collects labor data with comparable grouping by economic activities within the fisheries sector, but also experiences significant underreporting of gender disaggregated data with an average of $27 \%$ of countries reporting gender (Gee and Bacher, 2017).

Such data seems to be more readily available in non-EU Scandinavian countries, including Norway and Iceland that maintain fisheries databases where gender is demarcated. The National Statistical Institute in Iceland maintains a public database that contains economic and social data and includes a detailed labor force survey with gender disaggregated data for those employed as "agricultural and fishery workers". Similarly, Norway's Directorate of Fisheries ${ }^{3}$ tracks fisheries participants by gender, age, and county of residence, for those for whom fishing is either a primary or secondary occupation, although the data in the Sami regions seems to be less well populated. Fisheries and Oceans Canada ${ }^{4}$ also similarly tracks fisheries harvesters with personal information (names and birth years) available in some regions, although not necessarily universally across both Atlantic and Pacific fisheries. For example, the study conducted by Neis et al. (2013) in Canada utilized data that was provided by the Professional Fish Harvesters Certification Board, which contained data on a scale that denotes crew members from permit holders, but this information is not publicly available and

\footnotetext{
${ }^{2} \mathrm{http} / / / \mathrm{www}$.fao.org/fishery/statistics/software/en

${ }^{3}$ https://www.fiskeridir.no/English/Fisheries/Statistics/Fishermen-fishingvessels-and-licenses

${ }^{4}$ https://www-ops2.pac.dfo-mpo.gc.ca/vrnd-rneb/index-eng.cfm
}

is specific to Newfoundland and Labrador ${ }^{5}$. In addition to the aforementioned databases, another source of secondary data used was by Göncüoð̆lu and Ünal (2011) where license holder data was directly examined and gender was assigned based on known Turkish gender naming conventions.

The data sources presented speak to the difficulty in the lack of reliable gender disaggregation currently available across the study countries. Due to this systematic gap, the vast majority of the literature on women's engagement is effectively based on qualitative research methods to elucidate how women participate in specific fisheries or fishing communities and the effects of management changes and fisheries crises on that participation. A known tradeoff, the nature of some qualitative studies may produce dense information and "thick description," but these studies tend to have limited geographic coverage and sometimes restricted generalizability of results, which potentially constrains the impetus for policymakers to consider them in decision-making (Weiss, 1968; Jick, 1979; Yin, 1994; Myers, 2000; Schofield, 2002; Smith, 2018). Therefore, in the next section of this paper we propose using a new method to predict the gender of individuals in fisheries datasets using limited personal information, thus creating the possibility for various quantitative analyses, and, furthermore, coupling them with qualitative research to illuminate multiple dimensions of women's participation that may not be readily gleaned from the data.

\section{A METHOD FOR EXAMINING WOMEN'S FISHERIES ENGAGEMENT APPLIED TO ALASKA}

The following section focuses on the presentation of a mixedmethods approach to examine women's direct and indirect participation in commercial marine fisheries. We address the prominent methodological gap in the literature resultant from a lack of gender disaggregated data and integrate a qualitative

${ }^{5}$ https://www.pfhcb.com/ 
methodology to explore the dominant themes in women's participation in a new context. Women's direct participation is illuminated using a method that identifies the gender of commercial harvesters from commonly collected data on landings and permit records. Indirect participation is examined through focus groups with facilitated discussion about intrafamily patterns of fisheries participation and responses to changing fishing conditions, as well as women's participation in fisheries beyond the family unit. This mixed-methods approach was employed specifically in Alaska fisheries, which are multifaceted in scale, gear, proximity to shore, duration, and seasonality as well as being ecologically rich and diverse. Furthermore, we demonstrate the application of this method to the harvesting sector, although it could be similarly applied to the processing sector to examine women's participation in post-harvest activities and families engaged strictly in processing activities.

\section{Predicting Gender for Harvesters in Alaska Fisheries}

In Alaska, detailed harvest records have been collected since the 1970s that include fish landings and revenues, which allow researchers to track individual's participation over time. Coupled with personal information, including the individual's name and birth year, this harvest data can be gendered using the Gender (Mullen, 2019) and genderizeR (Wais, 2016) packages for $\mathrm{R}$ version 3.4.0 ( $\mathrm{R}$ Core Team 2013) that predict the probability of the gender of individuals (Blevins and Mullen, 2015; Wais, 2016). The "Gender" package predicts the gender of the first name by using an individual's birth year or a range of years within the United States Social Security Administration (SSA) name database, Integrated Public Use Microdata Series (IPUMS) and North Atlantic Population Project (NAPP) databases. For our analysis, the SSA method was used to predict gender based on first name and individual birth years (SSA_BY) and again for the full range of available years from 1890 to 2012 (SSA1890_2012). The United States SSA name database includes names that appear more than five times in a given year. IPUMS utilizes the United States census data from 1789 to 1930, and NAPP uses census microdata from Canada, Great Britain, Denmark, Iceland, Norway, and Sweden from 1801 to 1910. The "genderizeR" package utilizes social media data from 79 countries and is accessed by an application programming interface that is regularly updated.

Before incorporating a gender attribute into Alaska fisheries harvest data, we first examined the accuracy of the gender prediction methods within the two $\mathrm{R}$ packages utilizing three sample datasets with known gender for Alaska and Washington residents (the top two states for participants in Alaska fisheries) voter registration data from Alaska and Washington and birth certificate data from Alaska. The Alaska voter records contained approximately 512,366 observations for individuals registered to vote between 1967 and 2017; Washington voter data includes 4,686,967 records for those born between 1900 and 2000; and, Alaska birth certificate data contained 14,620 observations for those born between 1986 to 2015 and does not include names that occur less than five times in a given year to protect individuals confidentiality. The distributions of women across these three datasets were $49.14 \%$ for Alaska voters, 51.93\% for Washington voters, and $48.95 \%$ for Alaska birth certificates.

Because not all names are able to have their gender predicted with each method, we wanted to create an accuracy ranking for the methods so that the gender prediction would be based on a stepwise application of the methods. Depending on the database, the name may not meet the probability or count (for genderizeR) cutoff for gender prediction or be available at all in the underlying dataset. The proportion cutoff was set to $90 \%$ for all methods (the proportion of people with the given name that have that gender in the dataset), and for genderizeR only names with counts greater than or equal to 100 were taken into account (Wais, 2016). We tested all of the gender identification methods on the three datasets, except the SSA by birth year method was not tested on the Alaska voter registration data, because this data does not include birth year information. In order to determine the accuracy of each method, we applied statistics commonly utilized to determine the accuracy of diagnostic tests - sensitivity and specificity and the receiver operating characteristics (ROC) analysis (Zhou et al., 2002; Gatsonis and Paliwal, 2006; Leeflang et al., 2008). The accuracy ranking of the methods was then utilized as an order of application of the methods to create a predicted gender variable for each observation, and the accuracy of this overall gender prediction was examined using the same diagnostic metrics.

Similarly to Wais (2016), we examined the accuracy of the prediction methods in the $\mathrm{R}$ packages using several different probability cutoffs, the results of which are available upon request from the authors. There is an inherent tradeoff between accuracy and eliminating observations from being gendered with different probability cutoffs. We found that utilizing the $90 \%$ probability cutoff for the gender determination provided for overall accuracy with an area under the ROC Curve (AUC) above 0.9 for each of the methods and the overall gender prediction, while limiting the number of observations that would not be gendered, Table 2. This AUC is in the "excellent" range according to commonly utilized classifications for the AUC for diagnostic tests (Zhu et al., 2010). The sensitivity refers to the method's ability to accurately predict females and specificity to predict males. The differences in specificity and sensitivity show that the methods are slightly less accurate in predicting women's than men's names with higher values on average for sensitivity than specificity, consistent with previous studies (Blevins and Mullen, 2015; King et al., 2017). Nevertheless, taken together the methods have an accuracy of over 0.95 in predicting women so that no significant differences are expected in results. The differences in the number of observations by method for each dataset reflects how many observations met the $90 \%$ probability cutoff or the count of names for the genderizeR method. The SSA by birth year was the most accurate in predicting gender and also accounts for changes in naming conventions over time (Blevins and Mullen, 2015). Based on their accuracy ranking, the order of application of gender prediction methods is SSA by birth year, SSA 1890 to 2012, genderizeR, IPUMS, and NAPP. 
TABLE 2 | Accuracy metrics for gender identification methods and the overall predicted gender, including sensitivity and specificity (accuracy of identifying females and males, respectively) and the area under the receiver operating characteristic curve (AUC).

\begin{tabular}{|c|c|c|c|c|c|c|}
\hline \multirow[b]{2}{*}{ Data source } & \multicolumn{5}{|c|}{ Gender Identification Method } & \multirow[b]{2}{*}{ Predicted gender } \\
\hline & SSA_BY & SSA1890_2012 & genderizeR & IPUMS & NAPP & \\
\hline \multicolumn{7}{|l|}{ Alaska birth } \\
\hline Sensitivity & 99.93 & 99.88 & 96.6 & 82.11 & 83.7 & 94.68 \\
\hline Specificity & 99.48 & 99.97 & 97.8 & 99.37 & 98.5 & 98.3 \\
\hline AUC & 0.997 & 0.999 & 0.972 & 0.907 & 0.911 & 0.965 \\
\hline Observations & 11,877 & 11,674 & 10,348 & 11,188 & 9,004 & 12,855 \\
\hline \multicolumn{7}{|l|}{ Alaska voter } \\
\hline Sensitivity & - & 99.2 & 98.14 & 91.55 & 90.05 & 97.33 \\
\hline Specificity & - & 99.4 & 98.25 & 99.53 & 98.52 & 98.06 \\
\hline AUC & - & 0.993 & 0.982 & 0.955 & 0.943 & 0.977 \\
\hline Observations & - & 471,168 & 426,074 & 408,719 & 384,794 & 497,405 \\
\hline \multicolumn{7}{|c|}{ Washington voter } \\
\hline Sensitivity & 99.22 & 98.95 & 98 & 94.33 & 89.05 & 97.36 \\
\hline Specificity & 99.33 & 99.25 & 98.14 & 99.72 & 98.19 & 97.96 \\
\hline AUC & 0.993 & 0.991 & 0.981 & 0.97 & 0.936 & 0.977 \\
\hline Observations & $4,184,523$ & $4,285,052$ & 3,885,033 & $3,178,620$ & $3,431,639$ & $4,520,121$ \\
\hline
\end{tabular}

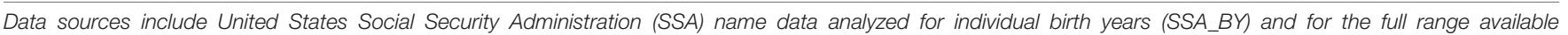
(SSA1890_2012), social media data (genderizeR), the Integrated Public Use Microdata Series (IPUMS), and the North Atlantic Population Project (NAPP).

A gender attribute was incorporated to the Alaska fisheries participation data applying the order of gender prediction methods determined with the sample data, with 42,091 permit holders gendered, see Table 3. A detailed discussion of these results and women's participation in Alaska fisheries is provided in Szymkowiak (2020); the summary herein is intended to describe how the application of this gender prediction method illuminated a comprehensive examination of harvesters in Alaska fisheries. A total of 907 permit holders (accounting for $2.1 \%$ of all permit holders and $1.93 \%$ of the observations) did not have gender determined due to missing names, names that were not available in the underlying gender data source, or those did not meet the probability or count cutoff.

Because the examination of permit data constrains the analysis to a vested class of harvesters, and one that is often dominated by men, we wanted to broaden the spectrum of participation that we considered in our analysis to include crewmembers. Crew licenses are issued annually to anyone that intends to participate as part of commercial harvesting crew in an Alaska fishery and the resulting license data includes a number of fields that lend themselves to examining gendered participation. In particular, the data includes the individual's name, birth date, residency, and self-identified gender, although the gender field is not consistently populated even for the same individual over time. In order to comprehensively populate gender in this data, we first filled in individuals' genders based on their name and birth date and information on their gender provided elsewhere in the data. For individuals for whom gender information was not available in the data at all, we used the gender prediction method described above for permit holders. A total of 37,737 observations within the crew license database had gender predicted using this method, representing $6.9 \%$ of the total number of crew licenses in the data, with 3,052 observations for which gender was not available and could not be predicted. Details on the order of application of the gender methods to permit holders are presented in Table 4.

Figures 3, 4 present women's and men's participation trends as crew and permit holders within Alaska fisheries from 1993 to 2017. Whereas women represent a marginally, but statistically significant proportion of permit holders over that time frame (Szymkowiak, 2020), the comparison with crew license data reveals that women engage more in the latter contingent of the harvesting sector, and at an increasing rate over time. While men continue to dominate both groups, their participation as crew has been declining over the time series and at an increasing rate over the last several years. Although women's participation as crew has been growing, as of 2017 women only account for $17.7 \%$ of crew; this represents a $4.4 \%$ increase since 1993 with half of the growth attributable to the last nine years of the time series. Concurrently, women's representation among permit holders has fluctuated around $11 \%$ to $12 \%$.

The differences in women's participation as crew and permit holders may reveal various facets of fisheries access, engagement, and upward mobility. Women's proportionally greater representation among crew license holders may point to their supportive roles of family fishing operations or greater access into these entry level positions. While their marginally smaller representation among permit holders may in turn reflect lowered access into the more empowered positions in fisheries for women. This divergence may reveal gender differences in upward mobility, which can be attributed to a variety of factors including differing social responsibilities, access to capital, norms and preferences. It is the intersection of these factors with policies that exacerbate or attenuate gender disparities in access and upward mobility that necessitate further exploration and evaluation in the Alaska context as elsewhere. What these figures indicate is that the ability to predict gender for various types of participants 
TABLE 3 | Number and percent of Alaska fishery permit holders that had gender predicted by each method.

\begin{tabular}{|c|c|c|c|c|c|c|}
\hline \multirow[b]{2}{*}{ Method } & \multicolumn{3}{|c|}{ Number of permit holders by method } & \multicolumn{3}{|c|}{ Percent of gendered permit holders by method } \\
\hline & Women & Men & Total & Women & Men & Total \\
\hline SSA1890_2012 & 328 & 1,246 & 1,574 & $5.2 \%$ & $3.48 \%$ & $3.74 \%$ \\
\hline genderizeR & 474 & 573 & 1,047 & $7.51 \%$ & $1.6 \%$ & $2.49 \%$ \\
\hline IPUMS & 86 & 271 & 357 & $1.36 \%$ & $0.76 \%$ & $0.85 \%$ \\
\hline
\end{tabular}

TABLE 4 | Number and percent of Alaska fishery crew license records that had gender predicted by each method.

\begin{tabular}{|c|c|c|c|c|c|c|}
\hline \multirow[b]{2}{*}{ Method } & \multicolumn{3}{|c|}{ Number of crew members by method } & \multicolumn{3}{|c|}{ Percent of gendered crew members by method } \\
\hline & Women & Men & Total & Women & Men & Total \\
\hline SSA1890_2012 & 478 & 1,972 & 2,450 & $7.11 \%$ & $6.36 \%$ & $6.49 \%$ \\
\hline genderizeR & 435 & 639 & 1,074 & $6.47 \%$ & $2.06 \%$ & $2.85 \%$ \\
\hline IPUMS & 184 & 748 & 932 & $2.74 \%$ & $2.41 \%$ & $2.47 \%$ \\
\hline
\end{tabular}

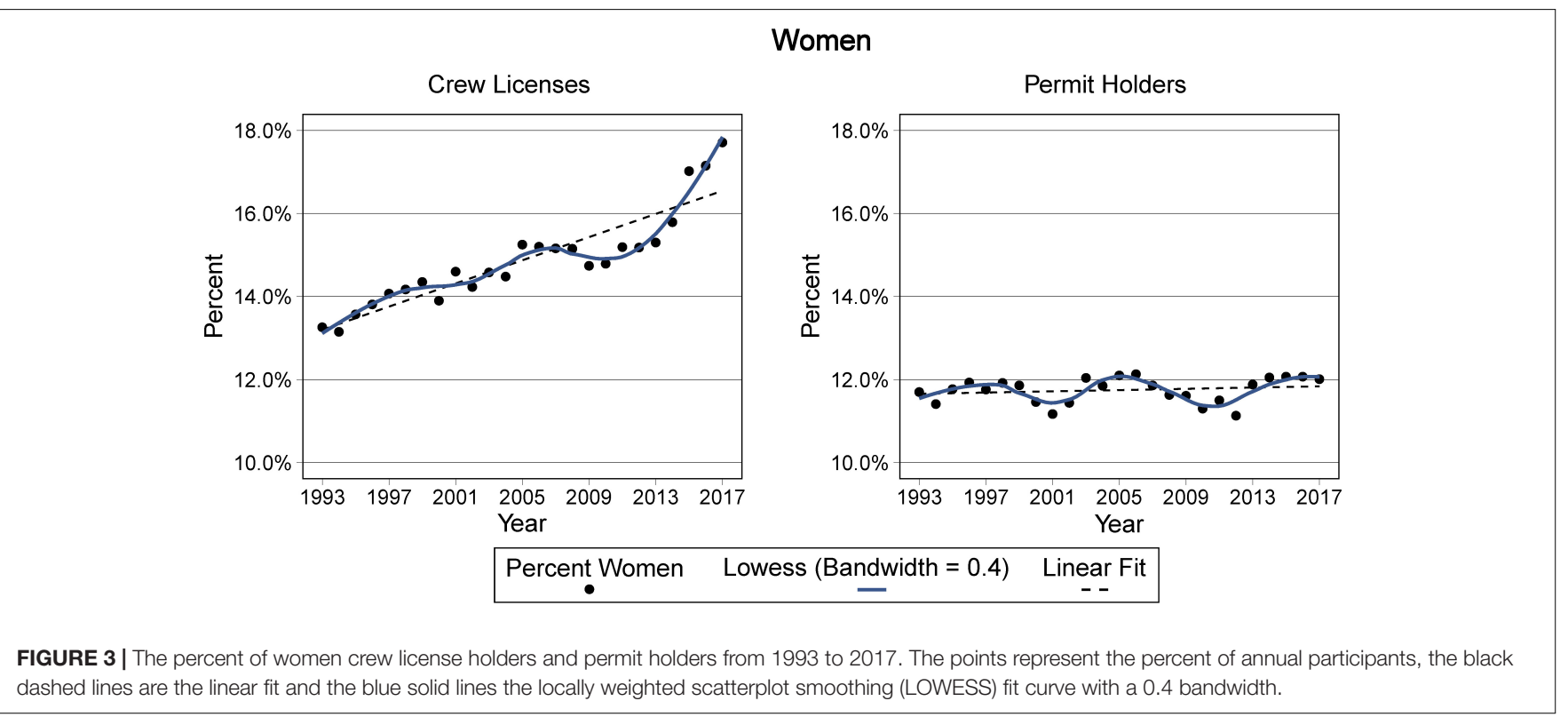

in fisheries can reveal gender disparities and the necessity for understanding women's access into fisheries at multiple levels. Simple examination of the data reveals the gender disparity in both crew and permit holders, setting the foundation for the reevaluation of gender blind management practices.

\section{Focus Groups: Illuminating Dimensions of Women's Participation in Alaska Fisheries}

Whereas the inclusion of a gender attribute into fisheries datasets will help to illuminate direct fisheries participation patterns from men and women, the nature of quantitative methods will largely be limited to how that participation manifests itself and responds to various variables, to the extent that those too can be incorporated. Yet, as illuminated above in the thematic coverage of the literature on women's fisheries participation, there are numerous, multifaceted dimensions of that participation many of which may not be observable in data. Qualitative methods, some of which have already been applied to examine women's fisheries participation around the world, can be used to gather data and information about these other dimensions. Coupling qualitative data with quantitative methods can facilitate examining multiple dimensions of women's direct and indirect 


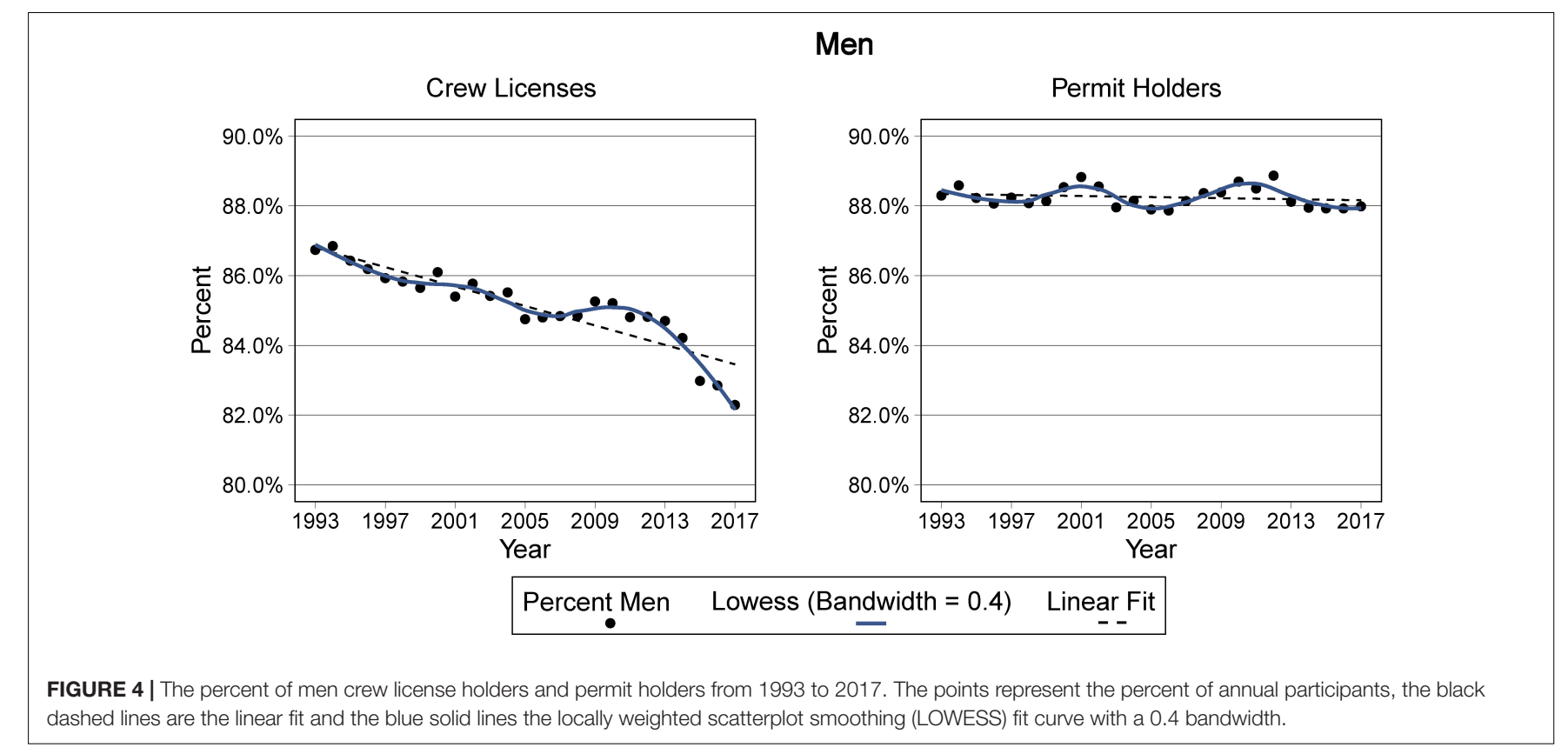

participation and the factors that affect it, including sociocultural trends and evolving norms, governance and management changes, as well as local- and macro- economics. The following section briefly describes the application of focus groups in the context of examining women's participation in Alaska fisheries, focusing specifically on how this approach can provide rich discussion of multiple dimensions of this participation.

For the purposes of examining women's engagement across Alaskan fishing communities, to inform dimensions of direct participation not gleaned from the data and facets of indirect participation, focus groups were employed. Many of Alaska's fishing communities are geographically isolated and have substantial variability in locally available species, which results in highly localized fishing engagement dynamics manifest in diverse fleet compositions. Focus groups provide a means of conducting systematic qualitative research across disparate communities in a resource constrained study environment (time, budget, and human capital). Furthermore, analysis of the focus group discourse can include comparison of inter-community and inter-fleet dynamics and provide some context for determining conceptual reliability in thematic areas that emerge across the groups.

In order to be able to examine fishing family dynamics and women in Alaska fisheries more broadly across a variety of communities and fishing fleets, a maximum variation sampling design was implemented (Creswell and Poth, 2018). The sampling frame targeted study sites and participants across specified criteria to understand fishing family dynamics, experiences of gender in fisheries, and adaptation strategies across a broad spectrum of experiences, specific to target fisheries, history of fishing, gender, age, and family contexts (Tremblay, 1957; Krueger and Casey, 2000). In total, seven focus groups were held across the largest fishing communities in the Gulf of Alaska, in terms of ex-vessel revenues and vessels - Anchorage, Cordova, Homer, Juneau, Kodiak, Petersburg, and Sitka. A total of 102 participants attended the focus groups, 59 of whom were women,

TABLE 5 | Distribution of themes across the seven focus groups in Gulf of Alaska communities.

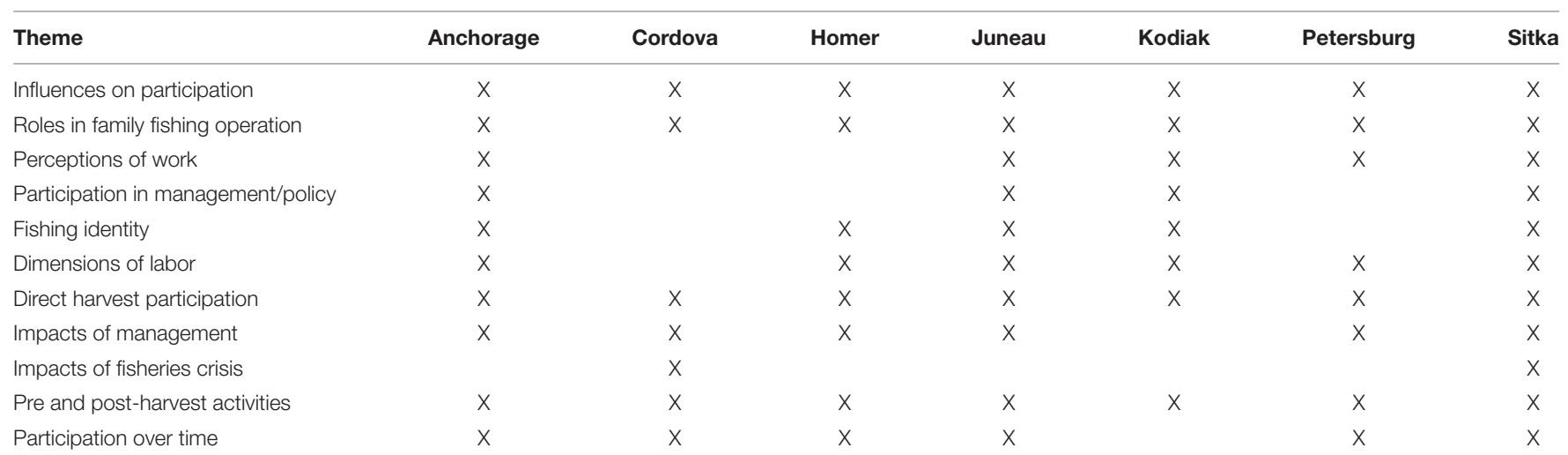


with an age range of 15 to 70 and an average of 45 (based on estimations as ages were not directly solicited); these participants represented experience across 20 distinct fisheries.

The framework of the two-hour focus groups was intended to provide a venue for illuminating dimensions of women's direct and indirect fisheries participation within and external to the family unit. The topic areas of discussion were: (1) family roles and gender divisions of labor; (2) impacts of management, environmental, economic, and social conditions on fishing family dynamics; and (3) the future of fishing families and women in Alaska fisheries. Process agendas and interview guides were employed to elicit spontaneous and multi-layered responses with respect to these topics (Kidd and Parshall, 2000; Krueger and Casey, 2000). The focus groups provided a venue for discussing the multi-faceted nature of women's indirect participation in Alaska fisheries, their adaptive role in fishing families, and dimensions of direct participation. The sessions were recorded with the informed consent of the participants, transcribed verbatim, and entered into MAXQDA, a qualitative data analysis program, for thematic coding using grounded theory (Strauss and Corbin, 1998).

The discussions across the focus groups encompassed all of the themes that have been identified in the literature on women's participation in fisheries. The results of these focus groups are discussed in detail in Szymkowiak (2020) and are only summarized here for the purposes of describing their representativeness of themes discussed within the literature on women's fisheries participation. All of the themes that are discussed in the literature on women's participation were captured across the seven focus groups, Table 5. Although the distribution of these themes varies, on average $81 \%$ of the themes were covered within each of the focus groups.

The focus groups were particularly effective at exploring influences on women's participation, their roles in family fishing operations, direct harvest participation, and pre- and postharvest activities - topics that were covered across all seven groups. In doing so, they elucidated multiple factors that contribute to women's harvesting participation that may not be derived from data but help to explain patterns within it. According to focus group participants, women continue to face substantial barriers to direct harvesting engagement including superstitions about them as bad luck on boats, stereotypes about physical abilities, and harassment, which contribute to their relatively small numbers as permit holders (Szymkowiak, 2020). Although women's primary access point into fisheries continues to be through fishing families, participants noted that within these families they are also the principal child caregivers, which often results in them staying shoreside and even relinquishing their own permit to their male partner. Support of family operations also contributes to their greater participation rates as crewmembers and to their dominance in pre- and post-harvest activities like net mending, direct marketing, and paperwork that are not tracked in databases (Szymkowiak, 2020).

Thus the application of focus groups in this context demonstrates the utility of this method in terms of gathering information about the multi-faceted nature of women's engagement in fisheries. The discussion spoke to manifest trends in the data about how women participate as direct harvesters that could not be elucidated without a qualitative tool. Furthermore, it provided for a much more expansive understanding of women's engagement in fisheries beyond direct harvesting participation than could be revealed through data exploration alone.

\section{DISCUSSION AND CONCLUSION}

Women's participation in Alaska fisheries and across developed countries, as evidenced by the themes that emerged in the literature and focus groups, is similar to that of women in developing countries. Contextualized within responsiveness to family conditions and numerous influences that have largely manifested as barriers to direct harvesting participation, women in the study regions have mostly engaged in fisheries through family operations and participation in the pre and post harvesting sectors.

However, there is also indication that women's direct harvesting participation in developed countries may actually be more constrained than in developing countries. For example, within El Salvador and the Phillippines women represent an estimated $26 \%$ to $42 \%$ of all fishers, respectively (Gammage, 2004; Kleiber et al., 2014) while examining women's participation across different habitats in Pacific Island countries reveals that women can account for up to $90 \%$ of nearshore, coastal reef fishers (Kronen and Vunisea, 2009). In comparison, about 11\% to $12 \%$ of permit holders and $13 \%$ to $18 \%$ of crew in Alaska are estimated to be women and for other developed countries for which estimates are available, women comprise about $3 \%$ to $22 \%$ of fish harvesters (Szymkowiak, 2020). This may in part be due to the predominantly offshore nature of fishing in developed countries, which conflicts with women's other responsibilities. Furthermore, the capital intensive nature of fishing in developed countries coupled with the increasing institution of licensing schemes that limit access based on fishing history mean that historic barriers to women's participation such as taboos and stereotypes have carried over to the modern day (Frangoudes and Gerrard, 2019). On the contrary, in developing countries there is usually a significant nearshore harvesting sector, which tends to be dominated by women (Kleiber et al., 2015). However, the lack of gender-disaggregated data on fisheries across the world limits our capacity to make such comparisons to a relatively few countries in which case studies have been conducted.

The method presented in this study that provides for the inclusion of gender in fisheries datasets can serve to illuminate these types of patterns around the world. The success of the gender prediction method at predicting permit holder gender in Alaska as well as the high accuracy for the gender predictions on the sample datasets demonstrates the utility and accuracy of freely and readily available data packages that can be used to examine women's direct participation in fisheries. In countries where the underlying name database in the "Gender" package has less applicability, the "genderizeR" package provides a substitute that utilizes names from across the world. This is particularly applicable in contexts where high immigration rates and changes in naming conventions mean the derivation 
of gender from a name is not straightforward. In addition, training datasets with names and known gender can be used to develop machine learning algorithms that will readily predict gender with limited information that is specific to national naming conventions.

The gender prediction method is recommended as a means to augment existing data and is most useful in scenarios where participant databases exist. The inclusion of a gender attribute in fisheries data creates the opportunity for various quantitative analyses, examining inter alia patterns in women's participation, responses to changes in fishing conditions (socioeconomic, governance, ecological, etc.), and differences across communities and fisheries within the harvesting sector as well as pre and post-harvest activities. However, the gender prediction method does not address women's many contributions in supporting fisheries that do not have associated databases, omitting a large contingent of women in fisheries and ignoring their contribution to sustaining this industry. Quantitative analyses should, therefore, be coupled with qualitative methods that can illuminate the multifaceted nature of how women engage in fisheries. Indeed the application of focus groups across Alaska fishing communities demonstrates the utility of this method for capturing the multitude of diverse dynamics of women's fisheries participation that are evident in the literature. Especially in cases wherein a study has expansive geographic coverage, focus groups can limit the expenditure of resources while providing for discourse that can be used to both determine conceptual validity and examine inter-community variation across thematic areas, as well as both of these variants within communities between fleets.

However, the focus group method has a number of shortcomings that should be understood by researchers, especially when applied to examining gender dynamics. The participatory nature of focus groups may limit the discourse on topics that are sensitive due to both censoring and conformity (Carey and Ashby, 2012; Carey, 2016). For the purposes of this study, such dynamics could impede forthright discussions of barriers to women's participation and the effects on families (and women in particular) from changing fishery conditions. However, participatory research methods are particularly useful in contexts where group interaction may produce insights beyond what could be accomplished with individual interviews (Morgan, 1996; Wilkinson, 1998; Kidd and Parshall, 2000; Krueger and Casey, 2000) and have been utilized in other contexts to conduct research on fishing families and women in particular (Zvonkovic et al., 2000; Bene et al., 2007). Furthermore, for the purposes of this study, multiple data gathering techniques were employed that allowed for individualized input that should have mitigated any adverse group effects, including individual exercises, note sheets for additional feedback, and a summary of major findings from the focus group provided to each participant (Carey, 2016). The nature of focus group discourse, while generally considered to produce valid results for analytical purposes, also creates issues with reliability because of how preceding comments drive succeeding ones (Carey, 2016). In this study, issues with reliability were intended to be mitigated with repeated measures across communities targeting the same discussion topics (Carey, 2016).
In addition to providing a more comprehensive picture of women's engagement in fisheries, the combination of quantitative and qualitative methodologies also allows researchers to triangulate results and explore patterns. Triangulation has been utilized in both purely qualitative studies and mixed quantitative-qualitative studies, providing for cross validation when two or more distinct methodologies yield congruent results (Denzin, 1978; Jick, 1979; Carter et al., 2014). Triangulation may be particularly useful for examining research results when focus group methods are applied due to the issues with reliability inherent to the method noted above. In turn, patterns evident in data can be illuminated with group discussions that can contextualize behavior and changes in norms, fishery conditions, and broader socioeconomic trends.

The single biggest void in the literature, and one that has been emphasized consistently by leading researchers in the field, is a lack of gender disaggregated data in fisheries. Thus, women's participation has generally been examined using qualitative research methods. Whereas these methods may elucidate detailed information about women's participation in particular fisheries or specific communities, the generalizability of these types of studies is hindered by their limited temporal and spatial scale. Even in countries with numerous studies specific to women's engagement in fisheries, the dearth of data prevents researchers and managers from systematically, quantitatively examining women's participation; and, any estimates of women's participation are usually heavily qualified.

The ultimate contribution of this study is then to demonstrate a mechanism for integrating a gender attribute into fisheries data using limited personal information to examine women's direct participation in fisheries. This approach is supplemented with the application of qualitative methods to examine the dimensions of women's direct and indirect fisheries participation that are not readily derived from the data. The method is demonstrated for Alaska fisheries, showcasing how the incorporation of gender into fisheries datasets can illuminate gendered fisheries participation patterns and potentially differentiated access and upward mobility; while focus groups detail the influences on that participation and the variegated ways in which women engage in and contribute to the sustainability of fisheries.

This methodological approach supplements rather than substitutes well-articulated calls for gender disaggregated data and consideration of women's participation across multiple, often ignored and devalued links in the fishery value chain. By triangulating research findings with multiple methods and systematically, quantitatively examining women's participation in fisheries, the necessity for fisheries policies to be aware of women rather than to espouse to be gender blind can be bolstered with evidence of how profoundly gender may in fact affect participation and how fishery benefits are distributed across people.

\section{DATA AVAILABILITY STATEMENT}

The datasets generated for this study will not be made publicly available to ensure the confidentiality of respondents. The raw 
data supporting the conclusions of this article will be made available by the authors, upon reasonable request, to any qualified researcher.

\section{ETHICS STATEMENT}

Ethical review and approval were not required for this study with human participants in accordance with NOAA's institutional requirements. The participants provided written informed consent to participate in this study.

\section{AUTHOR CONTRIBUTIONS}

MS devised the project and its main conceptual ideas, conducted the focus groups, analyzed the quantitative and qualitative data, assisted in the literature review, coded the themes in the literature, and developed the manuscript. MR-R genderized the data, conducted the literature review, assisted in coding the literature themes, assisted in analyzing the quantitative data, and assisted in developing the manuscript. Both authors contributed to manuscript revision, and read and approved the submitted version.

\section{REFERENCES}

Abreu-Ferreira, D. (2000). Fishmonger and shipowners: women in Maritime Communities of Early Modern Portugal. Sixt. Century J. 31, 7-23.

Aguilar, L., and Castaneda, I. (2001). About Fishermen, Fisherwomen, Oceans and Tides: A Gender Perspective in Marine-Coastal zones. San Jose, CA: IUCN.

Angell, E. (2009). "Women in Sámi Fisheries in Norway-Positions and Policies," in Gender, Culture, and Northern Fisheries, ed. J. Kafarowski (Edmonton: Canadian Circumpolar Institute Press), 3-28.

Bates, J. (2006). Gendered spaces of industrial restructuring in resource peripheries: the case of the Corner Brook Region, Newfoundland. Tijdschr. Econ. Soc. Geogr. 97, 126-137.

Bavington, D., Grzetic, B., and Neis, B. (2004). The feminist political ecology of fishing down: reflections from Newfoundland and Labrador. Stud. Polit. Econ. 73, 159-182.

Becker, R. A., and Wilks, A. R. (2018). Maps: Draw Geographical Maps. Available online at: https://CRAN.R-project.org/package=maps (accessed October 25, 2019).

Bene, C., Macfayden, G., and Allison, E. (2007). Increasing the contribution of small-scale fisheries to poverty alleviation and food security. FAO Fisheries Technical Paper No. 481. Rome: FAO.

Binkley, M. (2000). Gender, fisheries and development. Womens Stud. Int. Forum 23, 323-332.

Blevins, C., and Mullen, L. (2015). Jane, John .. Leslie? A historical method for algorithmic gender prediction. Digit. Humanit. Q. 9.

Britton, E. (2012). Women as agents of wellbeing in Northern Ireland's fishing households. Marit. Stud. 11:16.

Calhoun, S., Conway, F., and Russell, S. (2016). Acknowledging the voice of women: implications for fisheries management and policy. Mar. Policy 74, 292-299.

Carey, M. A. (2016). Focus groups-What is the same, what is new, what is next? Qual. Health Res. 26, 731-733. doi: 10.1177/1049732316636848

Carey, M. A., and Ashby, J. A. (2012). Focus Group Research. Walknut Creek, CA: Left Coast Press.

\section{FUNDING}

This work was supported by NOAA's Office of Science and Technology. The views and opinions expressed in this paper are the authors' own, and do not necessarily reflect those of the National Oceanic and Atmospheric Administration, or the U.S. Department of Commerce.

\section{ACKNOWLEDGMENTS}

We would like to thank Jordan Watson for assisting with data gathering as well as Sarah Wise, Stephen Kasperski, and the reviewers of this journal for their useful comments on this work. We also thank the State of Alaska Health Analytics and Vital Records Section as well as the State of Alaska and Washington's Division of Elections for the data used in accuracy checks.

\section{SUPPLEMENTARY MATERIAL}

The Supplementary Material for this article can be found online at: https://www.frontiersin.org/articles/10.3389/fmars. 2020.00299/full\#supplementary-material

Carothers, C., and Chambers, C. (2012). Fisheries privatization and the remaking of fishery systems. Environ. Soc. 3, 39-59.

Carter, N., Bryant-Lukosius, D., DiCenso, A., Blythe, J., and Neville, A. J. (2014). The use of triangulation in qualitative research. Oncol. Nurs. Forum 41, 545547. doi: 10.1188/14.ONF.545-547

Collins, P. H. (1998). It's all in the family: Intersections of gender, race, and nation. Hypatia 13, 62-82.

Connelly, M. P., and MacDonald, M. (1991-1992). State policy, the household and women's work in the Atlantic fishery. J. Can. Stud. 26, 18-32.

Conway, F. D., Gilden, J., and Zvonkovic, A. (2002). Changing communication and roles: innovations in Oregon's fishing families, communities, and management. Fisheries 27, 20-29.

Crenshaw, K. W. (1989). Demarginalizing the intersection of race and sex: a black feminist critique of antidiscrimination doctrine, feminist theory and antiracist politics. Univ. Chic. Leg. Forum 140, 139-167.

Crenshaw, K. W. (1997). "Intersectionality and identity politics: learning from violence against women of color," in Reconstructing Political Theory: Feminist Perspectives, eds M. L. Shanley and U. Narayan (University Park, PA: Pennsylvania State University Press), 178-193.

Crenshaw, K. W., and Bonis, O. (2005). Mapping the margins: Intersectionality, identity politics, and violence against women of color. Cah. Genre 2, 51-82.

Creswell, J. W., and Poth, C. N. (2018). Qualitative Inquiry and Research DesignChoosing Among Five Approaches. Thousand Oaks, CA: SAGE Publications.

Davis, D. L. (1986). Occupational community and fishermen's wives in a Newfoundland fishing village. Anthropol. Q. 59, 129-142.

De Silva, D. A. M. (2011). Faces of Women in Global Fishery Value Chains: Female Involvement, Impact and Importance in the Fisheries of Developed and Developing Countries. NORAD/FAO Value Chain Project. Rome: Food and Agriculture Organization.

Denzin, N. K. (1978). The Research Act, 2nd Edn. New York, NY: McGraw-Hill.

Donkersloot, R. (2005). Ecological Crisis Social Change and the Life Paths of Young Alaskans: An Analysis of the Impacts of Shifting Patterns in Human-Environment Interaction in the Fisheries-Dependent Region of Bristol Bay Alaska. Graduate Student thesis, University of Montana, Missoula, MT. 
European Commission Directorate General for Fisheries (2000). The Role of Women in the Fisheries Sector. Brussels: European Parliament.

FAO (2016). Promoting Gender Equality and Women's Empowerment in Fisheries and Aquaculture. Rome: FAO.

FAO (2017). "Towards gender-equitable small-scale fisheries governance and development - a handbook," in Support of the Implementation of the Voluntary Guidelines for Securing Sustainable Small-Scale Fisheries in the Context of Food Security and Poverty Eradication (Rome, Italy: Food and Agriculture Organization of the United Nations).

Frangoudes, K. (2013). Women in Fisheries: A European Perspective. Brussels: European Parliament.

Frangoudes, K., Carrol, M., Holmyard, N., Marcianiak, B., Moço, C., PascualFernandez, J., et al. (2008). The Role of Women in the Sustainable Development of European Fisheries. Brussels: European Parliament.

Frangoudes, K., and Gerrard, S. (2019). "Gender perspective in fisheries: examples from the South and the North," in Transdisciplinarity for SmallScale Fisheries Governance, eds R. Chuenpagdee and S. Jentoft (Berlin: Springer).

Frangoudes, K., and Keromnes, E. (2008). Women in artisanal fisheries in Brittany, France. Development 51, 265-270.

Frangoudes, K., and O'Doherty, J. (2006). Legal recognition of women's contribution in fisheries and aquaculture in the European Union. Paper Presented at the Global Symposium on Gender and Fisheries: Seventh Asian Fisheries Forum, Penang.

Gammage, S. (2004). "The tattered net of statistics," in Gender Agenda - Women in Fisheries: a Collection of Articles from SAMUDRA Report. International Collective in Support of Fishworkers, ed. K. G. Kumar (Chennai: ICSF) 36-40.

Gatsonis, C., and Paliwal, P. (2006). Meta-analysis of diagnostic and screening test accuracy evaluations: methodologic primer. AJR 187, 271-281. doi: 10.2214/ AJR.06.0226

Gee, J., and Bacher, K. (2017). Engendering statistics for fisheries and aquaculture. Paper Presented at the Gender in Aquaculture and Fisheries: Engendering Security in Fisheries and Aquaculture, Bangkok.

Gerrard, S. (1995). When women take the lead: Changing conditions for women's activities, roles and knowledge in North Norwegian fishing communities. Soc. Sci. Inf. 34, 593-631.

Gerrard, S. (2009). “"I have always wanted to go fishing”: challenging gender and gender perceptions in the quota-oriented small-scale fishery of Finnmark, Norway," in Gender, Culture, and Northern Fisheries, ed. J. Kafarowski (Edmonton: Canadian Circumpolar Institute Press).

Göncüoð̋lu, H., and Ünal, V. (2011). Fisherwomen in the Turkish fishery, southern Aegean Sea. J. Appl. Ichthyol. 27, 1013-1018.

Gonzalez, B. Y. (2018). Perspectives from Select Women Working in Alaskan Commercial Fisheries. Graduate Student thesis, University of Rhode Island, Kingston, RI.

Gopal, N., Williams, M., Porter, M., Kusakabe, K., and Choo, P.-S. (2014). Guest Editorial: gender in aquaculture and fisheries-navigating change. Asian Fish. Soc. 27, 1-14.

Grzetic, B. (2004). Women Fishes these Days. Halifax, NS: Fernwood.

Hall-Arber, M. (1996). Hear Me Speak: Italian and Portuguese Women Facing Fisheries Management [in New England]. Anthropol. Q. 38, 221-248.

Harper, S., Zeller, D., Hauzer, M., Pauly, D., and Sumaila, U. R. (2013). Women and fisheries: Contribution to food security and local economies. Mar. Policy $39,56-63$.

Helander-Renvall, E. (2009). "Beyond the Pale: Locating Sea Sami Women Outside the Official Fisheries Discourse in Northern Norway," in Gender, Culture, and Northern Fisheries, ed. J. Kafarowski (Edmonton: Canadian Circumpolar Institute Press), 189-199.

Jick, T. D. (1979). Mixing qualitative and quantitative methods: Triangulation in action. Adm. Sci. Q. 24, 602-611.

Júlíusdóttir, M., Skaptadóttir, U. D., and Karlsdóttir, A. (2013). Gendered migration in turbulent times in Iceland. Norsk geografisk tidsskrift 67, $266-275$.

Kafarowski, J. (2009). “'It's our land too": inuit women's involvement and representation in arctic fisheries in Canada," in Gender, Culture, and Northern Fisheries, ed. J. Kafarowski (Edmonton: Canadian Circumpolar Institute Press), 3-28.
Karlsdóttir, A. (2009). "Are living fish better than dead fillets? The invisibility and power of Icelandic women in Aquaculture and the Fishing Economy," in Gender, Culture, and Northern Fisheries, ed. J. Kafarowski (Edmonton: Canadian Circumpolar Institute Press), 3-28.

Keough, W. (2012). "Good Looks Don't Boil the Pot": Irish-Newfoundland Women as Fish (-Producing) Wives. J. Women Cult. Soc. 37, 536-544. doi: $10.1086 / 662687$

Kidd, P., and Parshall, M. (2000). Getting the focus and the group: Enhancing analytical rigor in focus group research. Qual. Health Res. 10, 293-308. doi: $10.1177 / 104973200129118453$

King, M., Bergstrom, C., Correll, S., Jacquet, J., and West, J. (2017). Men set their own cites high: gender self-citation across fields over time. Socius 3, 1-22. doi: $10.1177 / 2378023117738903$

Kleiber, D., Frangoudes, K., Snyder, H. T., Choudhury, A., Cole, S. M., Soejima, K., et al. (2017). "Promoting gender equity and equality through the small-scale fisheries guidelines: experiences from multiple case studies," in The SmallScale Fisheries Guidelines. MARE Publication Series, Vol. 14, eds S. Jentoft, R. Chuenpagdee, M. J. Barragán-Paladines, and N. Franz (Cham: Springer), 737-759.

Kleiber, D., Harris, L. M., and Vincent, A. C. J. (2014). Improving fisheries estimates by including women's catch in the Central Philippines. Can. J. Fish. Aquat. Sci. $71,656-664$.

Kleiber, D., Harris, L. M., and Vincent, A. C. J. (2015). Gender and small-scale fisheries: a case for counting women and beyond. Fish Fish. 16, 547-562.

Kronen, M., and Vunisea, A. (2009). Fishing impact and food security-Gender differences in finfisheries across Pacific Islands countries and culture groups. SPC Women Fish. Inf. Bull. 19, 3-10.

Krueger, R. A., and Casey, M. A. (2000). Focus Groups. A Practical Guide for Applied Research, 3 Edn. Thousand Oaks, CA: Sage Publications.

Lavoie, A., Lee, J., Sparks, K., Hoseth, G., and Wise, S. (2019). Engaging with women's knowledge in Bristol bay fisheries through oral history and participatory ethnography. Fisheries 44, 331-337. doi: 10.1002/fsh.10271

Leeflang, M., Deeks, J., Gastsonis, C., and Bossuyt, P. (2008). Systematic reviews of diagnostic test accuracy. Ann. Intern. Med. 149, 889-897.

MacDonald, M., Neis, B., and Murray, G. (2008).. State Policy, Livelihood Protection and Gender on Canada's East Coast. Int. J. Can. Stud. 38, 149-180

McCay, B. (2003). "Women's Rights, Community Survival, and the Fisheries Cooperative of Fogo Island," in Retrenchment and Regeneration in Rural Newfoundland, ed. R. Byron (Toronto: University of Toronto Press), 158-176.

Mercier, L. (2001). Reworking Race, Class, and Gender into Pacific Northwest History. Front. J. Women Stud. 22, 61-74.

Morgan, D. L. (1996). Focus Groups as Qualitative Research, Vol. 16. Thousand Oaks, CA: Sage publications.

Mullen, L. (2019). Genders: Predict Gender from Names Using Historical Data. Available online at: https://github.com/ropensci/gender (accessed December 10, 2019).

Munk-Madsen, E. (1998). The Norwegian fishing quota system: another patriarchal construction? Soc. Nat. Resour. 11, 229-240.

Munk-Madsen, E. (2000). Wife the deckhand, husband the skipper: authority and dignity among fishing couples. Womens Stud. Int. Forum 23, 333-342.

Myers, M. (2000). Qualitative research and the generalizability question: standing firm with proteus. Qual. Rep. 4.

Nadel-Klein, J. (2000). Granny baited the lines: Perpetual crisis and the changing role of women in Scottish fishing communities. Womens Stud. Int. Forum 23, 363-372.

Neilson, A. L., Gabriel, R., Arroz, A. M., and Mendonça, E. (2014). "Perspectives about the Sea in the Azores: respecting narratives that sustain inshore fishing communities," in Social Issues in Sustainable Marine Fisheries Management, Vol. 9, eds J. Urquhart, T. Acott, and M. Zhao (Dordrecht: Springer), 319-338.

Neis, B. (1999). "Familial and social patriarchy in the Newfoundland fishing industry," in Fishing Places, Fishing People: Traditions and Issues in Canadian Small-Scale Fisheries, eds D. Newell and R. E. Ommer (Toronto: University of Toronto Press), 32-54.

Neis, B., Gerrard, S., and Power, N. G. (2013). Women and children first: the gendered and generational social-ecology of smaller-scale fisheries in Newfoundland and Labrador and northern Norway. Ecol. Soc. 18:64.

Ogle, D. H., and Schanning, K. F. (2012). Usage of "sex" and "gender". Fisheries 37, 271-272. 
Olson, J. (2011). Understanding and contextualizing social impacts from the privatization of fisheries: an overview. Ocean Coast. Manage. 54, 353-363.

Pettersen, L. T. (1996). Crisis management and household strategies in Lofoten: a question of sustainable development. Sociol. Ruralis 36, 236-248.

Pettersen, L. T. (2018). From household business to sharehold companies impacts on gender relations and influence in fisheries and fish farming in northern Norway. Marit. Stud. 122, 1-15. doi: 10.1007/s40152-018$0122-8$

Porter, M. (1985). She Was Skipper of the Shore-Crew:" Notes on the History of the Sexual Division of Labour in Newfoundland. LabourLe Travail 15, 105-123.

Power, N. G. (2005). The" modern fisherman": Masculinity in crisis or resilient masculinity? Can. Woman Stud. 24, 102-107.

Salmi, P., and Sonck-Rautio, K. (2018). Invisible work, ignored knowledge? Changing gender roles, division of labor, and household strategies in Finnish small-scale fisheries. Marit. Stud. 17, 213-221.

Sarkar, D. (2008). Lattice: Multivariate Data Visualization with R. New York, NY: Springer.

Schofield, J. W. (2002). "Increasing the generalizability of qualitative research," in The Qualitative Researcher's Companion, eds A. M. Huberman and M. B. Miles (Thousand Oaks, CA: SAGE), 171-203.

Skaptadóttir, U. D. (1996). Gender construction and diversity in Icelandic fishing communities. Anthropologica 1, 271-287.

Smith, B. (2018). Generalizability in qualitative research: Misunderstandings, opportunities and recommendations for the sport and exercise sciences. Qual. Res. Sport Exerc. Health 10, 137-149.

Strauss, A., and Corbin, J. (1998). Basics of Qualitative Research Techniques. Thousand Oaks, CA: Sage publications.

Szymkowiak, M. (2020). Genderizing Fisheries: assessing over thirty years of women's participation in Alaska fisheries. Mar. Policy 30, 747-756.

Szymkowiak, M., and Himes-Cornell, A. H. (2015). Towards individual-owned and owner-operated fleets in the Alaska Halibut and Sablefish IFQ program. Marit. Stud. 14:19.

Tremblay, M. (1957). The key informant technique: a nonethnographic application. Am. Anthropol. 59, 88-701.

Uden, M. (2009). "Gender Equality and Governance in Arctic Swedish Fisheries and Reindeer Herding," in Gender, Culture, and Northern Fisheries, ed. J. Kafarowski (Edmonton: Canadian Circumpolar Institute Press), 3-28.

Wais, K. (2016). Gender prediction methods based on first names with genderizeR. R J. 8, 17-37.

Walker, B. L. E., and Robinson, M. A. (2009). Economic development, marine protected areas and gendered access to fishing resources in a Polynesian lagoon. Gender Place and Cult. 16, 467-484. doi: 10.1080/09663690903 003983
Weiss, R. S. (1968). "Issues in holistic research," in Institutions and the Person Howard, eds S. Becker, B. Geer, D. Riesman, and R. Weiss (Chicago: Aldine), 342-350.

Wickham, H. (2009).. ggplot2: Elegant Graphics for Data Analysis. New York, NY: Springer-Verlag

Wilkinson, S. (1998). Focus groups in health research: exploring the meanings of health and illness. J. Health Psychol. 3, 329-348. doi: $10.1177 / 135910539800300304$

Williams, M. J. (2010). "Gender dimensions in fisheries management," in Handbook of Marine Fisheries Conservation and Management, eds R. Q. Grafto, R. Hilborn, D. Squires, M. Tait, and M. Williams (New York, NY: Oxford University Press), 72-96.

Williams, M. J., Porter, M., Choo, P. S., Kusakabe, K., Vuki, V., Gopal, N., et al. (2012). Guest editorial: gender in aquaculture and fisheries-moving the agenda forward. Asian Fish. Sci. 25, 1-13.

Yin, R. (1994). Case Study Research: Design And Method, 2 edn. Beverly Hills, CA: Sage.

Yodanis, C. L. (2000). Constructing gender and occupational segregation: a study of women and work in fishing communities. Qual. Sociol. 23, 267-290.

Zhao, M., Tyzack, M., Anderson, R., and Onoakpovike, E. (2013). Women as visible and invisible workers in fisheries: a case study of Northern England. Mar. Policy $37,69-76$.

Zhou, X. A., Obuchowski, N., and McClish, D. (2002). Statistical Methods in Diagnostic Medicine, 2 Edn. New York, NY: Wiley.

Zhu, W., Zeng, N., and Wang, N. (2010). "Sensitivity, specificity, accuracy, associated confidence interval and ROC analysis with practical SAS implementations," in Proceedings of the Nesug Health Care And Life Sciences, Baltimore, MD, 19.

Zvonkovic, A. M., McGraw, L. A., and Manoogian-O’Del, M. (2000). “A multimethod research project on commercial fishing families: multiple windows on resilient women and families," in Change and Resilience in Fishing, eds S. Hanna and M. Hall-Arber (Corvallis, OR: Oregon Sea Grant).

Conflict of Interest: The authors declare that the research was conducted in the absence of any commercial or financial relationships that could be construed as a potential conflict of interest.

Copyright (C) 2020 Szymkowiak and Rhodes-Reese. This is an open-access article distributed under the terms of the Creative Commons Attribution License (CC BY). The use, distribution or reproduction in other forums is permitted, provided the original author(s) and the copyright owner(s) are credited and that the original publication in this journal is cited, in accordance with accepted academic practice. No use, distribution or reproduction is permitted which does not comply with these terms. 